\title{
Comparison of the temporal release pattern of copeptin with conventional biomarkers in acute myocardial infarction
}

\author{
Youlan L. Gu • Adriaan A. Voors · Felix Zijlstra $\cdot$ Hans L. Hillege \\ Joachim Struck • Serge Masson · Tarcisio Vago • Stefan D. Anker • \\ Ad F. M. van den Heuvel • Dirk J. van Veldhuisen • Bart J. G. L. de Smet
}

Received: 1 March 2011 / Accepted: 1 July 2011/Published online: 16 July 2011

(C) The Author(s) 2011. This article is published with open access at Springerlink.com

\begin{abstract}
Background Early detection of acute myocardial infarction (AMI) using cardiac biomarkers of myocardial necrosis remains limited since these biomarkers do not rise within the first hours from onset of AMI. We aimed to compare the temporal release pattern of the C-terminal portion of provasopressin (copeptin) with conventional cardiac biomarkers, including creatine kinase isoenzyme (CK-MB), cardiac troponin T (cTnT), and high-sensitivity cTnT (hs-cTnT), in patients with ST-elevation AMI.
\end{abstract}

Y. L. Gu · A. A. Voors $(\bowtie) \cdot$ H. L. Hillege

A. F. M. van den Heuvel - D. J. van Veldhuisen .

B. J. G. L. de Smet

Department of Cardiology, Thorax Center, University Medical

Center Groningen, University of Groningen, Hanzeplein 1,

PO Box 30001, 9700 RB Groningen, The Netherlands

e-mail: a.a.voors@thorax.umcg.nl

F. Zijlstra

Thorax Center, Erasmus Medical Center,

Rotterdam, The Netherlands

J. Struck

Research Department, B.R.A.H.M.S. GmbH

(Part of ThermoFisher Scientific), Hennigsdorf, Germany

S. Masson

Department of Cardiovascular Research, Instituto Mario Negri, Milan, Italy

T. Vago

Laboratory of Endocrinology, Ospedale Luigi Sacco,

Milan, Italy

S. D. Anker

Applied Cachexia Research, Department of Cardiology,

Charité, Campus Virchow-Klinikum, Berlin, Germany
Methods We included 145 patients undergoing successful primary percutaneous coronary intervention (PCI) for a first ST-elevation AMI presenting within $12 \mathrm{~h}$ of symptom onset. Blood samples were taken on admission and at four time points within the first $24 \mathrm{~h}$ after PCI.

Results In contrast to all other markers, copeptin levels were already elevated on admission and were higher with a shorter time from symptom onset to reperfusion and lower systolic blood pressure. Copeptin levels peaked immediately after symptom onset at a maximum of $249 \mathrm{pmol} / \mathrm{L}$ and normalized within $10 \mathrm{~h}$. In contrast, CK-MB, cTnT, and hs-cTnT peaked after $14 \mathrm{~h}$ from symptom onset at a maximum of $275 \mathrm{U} / \mathrm{L}, 5.75 \mu \mathrm{g} / \mathrm{L}$, and $4.16 \mu \mathrm{g} / \mathrm{L}$, respectively, and decreased more gradually.

Conclusions Copeptin has a distinct release pattern in patients with ST-elevation AMI, peaking within the first hour after symptom onset before conventional cardiac biomarkers and falling to normal ranges within the first day. Further studies are required to determine the exact role of copeptin in AMI suspects presenting within the first hours after symptom onset.

Keywords Copeptin - Acute myocardial infarction . Biomarkers · Temporal release pattern · Troponin

\section{Introduction}

Acute myocardial infarction (AMI) is defined as a clinical cardiac event that is the consequence of myocardial necrosis caused by ischemia [1]. Its diagnosis is often based on symptoms, signs, and findings on the electrocardiogram (ECG), but in some patients these findings are non-diagnostic. In these patients, biochemical markers of myocardial necrosis, of which cardiac troponin and 
creatine kinase isoenzyme (CK-MB) are the preferred biomarkers, play a pivotal role [2,3]. A major drawback of these markers is their inability to detect myocardial necrosis in the first hours after symptom onset, since these cardiac biomarkers rise after hours from the onset of myocardial injury. While the outcome of AMI patients has improved considerably [4, 5], establishing a timely and correct diagnosis remains a challenge in patients presenting early after symptom onset without typical ECG findings.

Recently, the C-terminal portion of provasopressin (copeptin), a marker of acute endogenous stress and cardiovascular hemostasis [6], has emerged as a promising diagnostic marker for the detection of AMI in addition to conventional cardiac biomarkers of myocardial necrosis in patients presenting early after symptom onset [7, 8]. In these studies, addition of copeptin to cardiac troponin $\mathrm{T}$ (cTnT) improved the diagnostic accuracy of a measurement on admission in patients presenting with chest pain to an emergency department, especially in patients presenting within $3 \mathrm{~h}$ after symptom onset. However, although these studies have suggested that copeptin levels are elevated much earlier than CK-MB or cTnT and drop in the $6 \mathrm{~h}$ thereafter in patients with AMI, a comparison of temporal release patterns after the onset of AMI between copeptin and conventional cardiac biomarkers has not been made for more than $6 \mathrm{~h}$, when levels were still elevated. We therefore studied the temporal release pattern of copeptin and also studied its relationship with conventional cardiac biomarkers including the newly available high-sensitivity cTnT (hs-cTnT) by frequently sampling patients with STelevation AMI within the first $24 \mathrm{~h}$.

\section{Methods}

Patients and design

The HEBE III trial was a randomized clinical trial evaluating the effect of a single bolus of erythropoietin after successful percutaneous coronary intervention (PCI) for a first AMI on left ventricular ejection fraction. The study design and results of the main study have been previously described [9]. In brief, patients were eligible for the participation if undergoing successful primary PCI (defined as post-procedural thrombolysis in myocardial infarction (TIMI) flow $2 / 3$ through the culprit coronary artery) for a first AMI. AMI was defined as chest pain suggestive for an AMI, symptom onset $<12 \mathrm{~h}$ before hospital admission or $<24 \mathrm{~h}$ in case of ongoing ischemia, an ECG with ST-segment elevation $>1 \mathrm{mV}$ in 2 or more leads or a new left bundle branch block, and TIMI flow grade 0 or 1 on diagnostic coronary angiography. Exclusion criteria included: hemoglobin levels $>17.1 \mathrm{~g} / \mathrm{dL}(>10.6 \mathrm{mmol} / \mathrm{L})$ before PCI, anticipated additional revascularization within 6 weeks, atrial fibrillation, cardiogenic shock, end stage renal failure (creatinine $>220 \mu \mathrm{mol} / \mathrm{L}$ ), malignant hypertension, previous treatment with $\mathrm{RhEPO}$, blood transfusion $<12$ weeks before randomization, polycythemia vera, pregnancy or breast-feeding, concomitant inflammatory or malignant disease, the presence of other serious medical conditions, and recent trauma or major surgery. Primary endpoint was ventricular ejection fraction as assessed by planar radionuclide ventriculography at 6 weeks after PCI. The trial protocol was approved by the Medical Ethics Committee of our institution and is in accordance with the Declaration of Helsinki. In total, 529 patients were included in HEBE III. The current study was performed on all patients enrolled in the pre-specified neurohormonal substudy, with a total of 145 patients recruited at the University Medical Center Groningen, the Netherlands. Informed consent was obtained in all patients. There were no significant differences in baseline characteristics between the main trial and the current substudy.

\section{Blood sampling and assays}

Blood samples were taken immediately on admission and at 3, 6, and $24 \mathrm{~h}$ after PCI. Routine laboratory parameters including CK, CK-MB, and cTnT were determined with automated clinical chemistry methods immediately after withdrawal. Additional blood samples were collected using pyrogen-free tubes containing ethylenediaminetetraacetic acid plasma, and centrifuged and stored at $-80^{\circ} \mathrm{C}$ within $1 \mathrm{~h}$ of withdrawal until analysis was performed. Copeptin was detected in EDTA plasma with a commercially available sandwich immunoluminometric assay (CT-proAVP, B.R.A.H.M.S GmbH, Hennigsdorf, Germany) as described in detail previously $[8,10]$. The analytical detection limit of the assay was $0.4 \mathrm{pmol} / \mathrm{L}$, and the functional assay sensitivity (value with an interassay coefficient of variation $(\mathrm{CV})<20 \%)<1 \mathrm{pmol} / \mathrm{L}$. In a reference population of 5,000 participants of the Gutenberg Heart Study, the 95, 97.5, and 99th percentile were 9.8, 13, and $18.9 \mathrm{pmol} / \mathrm{L}$, respectively [7]. cTnT was measured with an electrochemiluminescence immunoassay (Roche Diagnostics, Mannheim, Germany). The analytical detection limit was $0.01 \mu \mathrm{g} / \mathrm{L}$, the $\mathrm{CV}$ was $10 \%$ at $0.03 \mu \mathrm{g} / \mathrm{L}$, and the 99th percentile in a healthy reference population was $0.01 \mu \mathrm{g} / \mathrm{L}$. In addition, hs-cTnT was determined (Roche Diagnostics). Hs-cTnT had a limit of detection of $0.003 \mu \mathrm{g} / \mathrm{L}$, the $10 \% \mathrm{CV}$ at $0.013 \mu \mathrm{g} / \mathrm{L}$, and a 99th percentile cutoff point of $0.014 \mu \mathrm{g} / \mathrm{L}$. For the current study, hs-cTnT had an interassay CV of 7.8, 4.6, and 4.3\%, at concentrations of $0.0233,1.869$, and $0.1176 \mu \mathrm{g} / \mathrm{L}$, respectively. CK was measured by photometry and CK-MB by 
immunoinhibition (both Roche Modular P, Roche Diagnostics GmbH, Mannheim, Germany). The estimated glomerular filtration rate (eGFR) was calculated using the simplified Modification of Diet in Renal Disease equation [11].

\section{Statistical analysis}

Data are expressed as mean \pm standard deviation or median (interquartile range) for continuous data and as number (percentage) for categorical variables. Copeptin values on admission were divided into quartiles to assess relationships with baseline characteristics. Continuous variables were compared using the two-sided student $t$ test or Mann-Whitney $U$ test if samples were not normally distributed. Categorical variables were analyzed with the Pearson $\chi^{2}$ test. Correlation between continuous variables was assessed with the Spearman's rank correlation coefficient. To analyze correlates of the copeptin level on admission, the STATA validation bootstrapping program, SWBOOT, was used to perform 100 bootstrapped repeats of multi-variable stepwise linear regression on candidate correlates of copeptin levels. After the SWBOOT run, the resulting validated candidate independent variables that were selected at least 50 times out of the 100 separate models were included in the final model and again entered into a stepwise linear regression model. In this validation run, the same regression procedure was used except that the alpha tail probability for an independent variable to enter the model was set at the conventional screening level of 0.05 and to remove of 0.1. STATA bootstrap estimation was used to estimate $95 \%$ confidence intervals. Continuous variables were introduced centered in the regression model. Copeptin was log transformed and centered. Time from symptom onset to blood sampling was calculated for all individual patients according to the actual sampling moment. A fractional polynomial parameterization of exposure was applied to investigate the relation between marker levels and the time from symptom onset to sampling moment. Fractional polynomials are a method of analyzing relationships that make no a priori hypothesis about their shape [12]. With this analysis, each exposure variable (copeptin, CK-MB, cTnT, and hs-cTnT) is expressed a polynomial of degree $>1$ to allow modeling of its non-linear relation. Because data could be assumed to be clustered (i.e., within patients), possible cluster effects were adjusted for by applying robust standard errors (i.e., option 'cluster' in the specific STATA regression commands). Statistical significance was considered as a two-tailed $p$ value $<0.05$. Statistical analyses were performed with SPSS version 16.0.2 (Chicago, IL, USA) and STATA version 11.0 (College Station, Texas, USA).

\section{Results}

\section{Baseline characteristics}

From the 145 patients included in this study, a baseline copeptin level was available in 130 patients. Baseline characteristics of these patients, according to quartiles of copeptin at hospital admission, are summarized in Table 1. Mean age of the total population was $61 \pm 12$ years and $76 \%$ was male. Copeptin levels were higher in patients with lower body mass index (BMI) and lower blood pressure on the admission. Higher levels of copeptin were particularly found in patients who presented early after onset of symptoms (Table 1). A shorter symptom onset to reperfusion time was correlated with a higher admission copeptin level $(r=-0.431, p<0.001)$. Copeptin levels on admission were not related to enzymatic infarct size as reflected in the peak of CK, CK-MB, or cTnT (Table 2).

\section{Correlates of admission copeptin level}

Univariable correlates of copeptin levels on admission included BMI, systolic and diastolic blood pressure, anterior MI, and time from symptom onset to reperfusion (Table 3). After multivariable adjustment, a higher copeptin level on admission was independently associated with a lower BMI, lower systolic blood pressure, and a shorter time from symptom onset to reperfusion.

Copeptin levels on admission compared to conventional cardiac biomarkers

Copeptin levels on admission exceeded the 99th percentile in $84.8 \%$ of patients reperfused within $3 \mathrm{~h}$ of symptom onset and in $100 \%$ of patients with symptom onset of less than $1 \mathrm{~h}$ (Table 4). In contrast, sensitivity was lower on admission for cTnT (39.4\%) and hs-cTnT (80.3\%). Elevation of copeptin and/or (hs-)cTnT beyond the 99th percentile reached the highest sensitivities at $90.9 \%$ for $\mathrm{cTnT}$ and $98.5 \%$ for hs-cTnT.

Temporal release pattern of copeptin compared to conventional cardiac biomarkers

Figure 1 shows the distinctively different temporal release pattern of copeptin in comparison to CK-MB, cTnT, and hs-cTnT. As illustrated, copeptin levels were at a maximum of $249 \mathrm{pmol} / \mathrm{L}$ immediately after symptom onset and normalized to below the upper reference limit (99th percentile) within $10 \mathrm{~h}$. In contrast, conventional cardiac biomarkers increased to their maximal levels at 14-16 h of 
Table 1 Baseline patient characteristics according to quartiles of copeptin on admission

\begin{tabular}{|c|c|c|c|c|c|c|}
\hline & \multicolumn{6}{|l|}{ Copeptin } \\
\hline & All $(n=130)$ & $\leq 15.50$ & $15.51-79.05$ & $79.06-179.00$ & $>179.00$ & $p$ \\
\hline \multicolumn{7}{|l|}{ Clinical } \\
\hline Age (years) & $61 \pm 12$ & $61 \pm 12$ & $60 \pm 9$ & $63 \pm 13$ & $62 \pm 12$ & 0.799 \\
\hline Male sex $[n(\%)]$ & $99(76)$ & $27(82)$ & $25(78)$ & $26(79)$ & $21(66)$ & 0.156 \\
\hline BMI $\left(\mathrm{kg} / \mathrm{m}^{2}\right)$ & $27(24-30)$ & $29(26-31)$ & $28(25-30)$ & $28(24-30)$ & $25(23-28)$ & 0.001 \\
\hline Systolic blood pressure (mmHg) & $122 \pm 23$ & $133 \pm 23$ & $125 \pm 22$ & $114 \pm 17$ & $116 \pm 23$ & 0.001 \\
\hline Diastolic blood pressure (mmHg) & $72 \pm 13$ & $77 \pm 12$ & $73 \pm 13$ & $69 \pm 11$ & $68 \pm 15$ & 0.016 \\
\hline Heart rate $(\mathrm{bpm})$ & $78 \pm 14$ & $82 \pm 14$ & $78 \pm 15$ & $76 \pm 12$ & $75 \pm 15$ & 0.179 \\
\hline Previous revascularization $[n(\%)]$ & $1(1)$ & $1(3)$ & $0(0)$ & $0(0)$ & $0(0)$ & 0.185 \\
\hline Hypertension $[n(\%)]$ & $50(39)$ & $12(36)$ & $11(37)$ & $14(44)$ & $13(41)$ & 0.608 \\
\hline Diabetes $[n(\%)]$ & $12(9)$ & $6(18)$ & $3(10)$ & $0(0)$ & $3(9)$ & 0.111 \\
\hline Current smoking $[n(\%)]$ & $32(25)$ & $10(30)$ & $8(27)$ & $8(25)$ & $6(19)$ & 0.289 \\
\hline Family history $[n(\%)]$ & $47(37)$ & $12(36)$ & $13(43)$ & $10(31)$ & $12(38)$ & 0.831 \\
\hline Hypercholesterolemia $[n(\%)]$ & $22(17)$ & $7(21)$ & $6(20)$ & $7(22)$ & $2(6)$ & 0.153 \\
\hline Symptom onset to reperfusion (min) & $180(135-270)$ & $265(177-427)$ & $205(157-272)$ & $150(104-202)$ & $155(120-210)$ & $<0.001$ \\
\hline \multicolumn{7}{|l|}{ Angiographic } \\
\hline No. of diseased vessels $[n(\%)]$ & & & & & & 0.911 \\
\hline 1 & $86(68)$ & $22(67)$ & $23(72)$ & $20(61)$ & $21(66)$ & \\
\hline 2 & $33(25)$ & $8(24)$ & $6(19)$ & $10(30)$ & $9(28)$ & \\
\hline 3 & $11(9)$ & $3(9)$ & $3(9)$ & $3(9)$ & $2(6)$ & \\
\hline Anterior AMI $[n(\%)]$ & $61(47)$ & $12(36)$ & $12(38)$ & $18(55)$ & $19(59)$ & 0.029 \\
\hline \multicolumn{7}{|l|}{ Biochemical } \\
\hline $\mathrm{eGFR}\left(\mathrm{mL} / \mathrm{min} / 1.73 \mathrm{~m}^{2}\right)$ & $95 \pm 23$ & $99 \pm 24$ & $95 \pm 24$ & $95 \pm 25$ & $88 \pm 17$ & 0.298 \\
\hline Sodium (mmol/L) & $139 \pm 2$ & $138 \pm 2$ & $139 \pm 2$ & $140 \pm 2$ & $140 \pm 2$ & 0.005 \\
\hline NT-proBNP (ng/L) & $98(57-324)$ & $178(68-402)$ & $79(49-146)$ & $93(43-421)$ & $92(40-215)$ & 0.140 \\
\hline
\end{tabular}

Data are expressed as mean $\pm \mathrm{SD}$, median (interquartile range), or number (percentage)

$A M I$ acute myocardial infarction, $B M I$ body mass index, $e G F R$ estimated glomerular filtration rate, $N T$-proBNP N-terminal pro-B-type natriuretic peptide, $P C I$ percutaneous coronary intervention

Table 2 Relationship between admission copeptin level and enzymatic infarct size

\begin{tabular}{lcccccc}
\hline & Copeptin & & & & \\
\cline { 2 - 6 } & All $(n=130)$ & $\leq 15.50$ & $15.51-79.05$ & $79.06-179.00$ & $>179.00$ & $p$ \\
\hline Max CK (U/L) & $1,526(872-2,935)$ & $1,522(903-3,094)$ & $1,423(868-2,738)$ & $1,686(786-2,753)$ & $1,472(733-3,206)$ & 0.731 \\
Max CK-MB $(\mathrm{U} / \mathrm{L})$ & $206(112-323)$ & $219(132-329)$ & $210(109-299)$ & $178(102-329)$ & $209(89-344)$ & 0.581 \\
Max troponin T $(\mu \mathrm{g} / \mathrm{L})$ & $4.9(2.0-7.9)$ & $4.9(2.5-8.3)$ & $4.4(2.3-8.1)$ & $5.3(2.0-7.0)$ & $3.9(1.6-9.1)$ & 0.537 \\
\hline
\end{tabular}

Data are expressed as median (interquartile range)

$C K$ creatine kinase, $C K-M B$ creatine kinase isoenzyme

symptom onset at a maximum of $275 \mathrm{U} / \mathrm{L}, 5.75 \mu \mathrm{g} / \mathrm{L}$, and $4.16 \mu \mathrm{g} / \mathrm{L}$ for $\mathrm{CK}-\mathrm{MB}$, cTnT, and hs-cTnT, respectively. The temporal release patterns of cTnT and hs-cTnT showed a similar curve. After $16 \mathrm{~h}$, cardiac biomarker levels decreased more gradually than copeptin, with $\mathrm{CK}$ MB falling slightly steeper than cTnT and hs-cTnT.

\section{Discussion}

Although copeptin has been recently described as a potential biomarker for the early detection of AMI, there is little detailed information about its release pattern during the early hours after the onset of AMI. In this study, we 
Table 3 Univariable and multivariable correlates of copeptin (log transformed)

\begin{tabular}{|c|c|c|c|c|c|c|c|}
\hline & \multicolumn{3}{|l|}{ Univariable } & \multicolumn{3}{|c|}{ Multivariable } & \multirow{2}{*}{$\begin{array}{l}\text { Number of } \\
\text { times selectec }\end{array}$} \\
\hline & Coefficient & $95 \% \mathrm{CI}$ & $p$ & Coefficient & $95 \% \mathrm{CI}$ & $p$ & \\
\hline BMI $\left(\mathrm{kg} / \mathrm{m}^{2}\right)$ & -0.135 & -0.193 to -0.0773 & $<0.001$ & -0.124 & -0.172 to -0.077 & $<0.001$ & 94 \\
\hline $\begin{array}{l}\text { Systolic blood } \\
\text { pressure }(\mathrm{mmHg})\end{array}$ & -0.024 & -0.034 to -0.013 & $<0.001$ & -0.021 & -0.030 to -0.012 & $<0.001$ & 82 \\
\hline $\begin{array}{l}\text { Diastolic blood } \\
\text { pressure }(\mathrm{mmHg})\end{array}$ & -0.031 & -0.050 to -0.012 & 0.002 & & & & \\
\hline Heart rate $(\mathrm{bpm})$ & -0.024 & -0.042 to -0.006 & 0.008 & & & & \\
\hline Anterior AMI & 0.556 & 0.056 to 1.056 & 0.030 & & & & \\
\hline $\begin{array}{l}\text { Time from symptom } \\
\text { onset to reperfusion (h) }\end{array}$ & -0.192 & -0.283 to -0.101 & $<0.001$ & -0.162 & -0.247 to -0.076 & $<0.001$ & 86 \\
\hline Admission sodium $(\mathrm{mmol} / \mathrm{L})$ & 0.173 & 0.070 to 0.275 & 0.001 & & & & \\
\hline
\end{tabular}

$A M I$ acute myocardial infarction, $B M I$ body mass index, $C I$ confidence interval

Table 4 Sensitivities of biomarkers on admission in the early hours after symptom onset

Data are expressed as number/ total number (percentage)

$c T n T$ cardiac troponin $\mathrm{T}$, $h s$-cTnT high-sensitivity cardiac troponin $\mathrm{T}$

Copeptin levels exceeding the a 99 th $(18.9 \mathrm{pmol} / \mathrm{L}),{ }^{\mathrm{b}} 97.5$ th (13 pmol/L), and ${ }^{\mathrm{c}}$ 95th ( $9.8 \mathrm{pmol} / \mathrm{L})$ percentile

\begin{tabular}{lcll}
\hline & $<1 \mathrm{~h}$ & $<2 \mathrm{~h}$ & $<3 \mathrm{~h}$ \\
\hline Copeptin $^{\mathrm{a}}$ & $10 / 10(100)$ & $34 / 37(91.9)$ & $56 / 66(84.8)$ \\
Copeptin $^{\mathrm{b}}$ & $10 / 10(100)$ & $34 / 37(91.9)$ & $59 / 66(89.4)$ \\
Copeptin $^{\mathrm{c}}$ & $10 / 10(100)$ & $36 / 37(97.3)$ & $61 / 66(92.4)$ \\
cTnT & $3 / 10(30)$ & $10 / 37(27.0)$ & $26 / 66(39.4)$ \\
hs-cTnT & $7 / 10(70)$ & $29 / 37(78.4)$ & $53 / 66(80.3)$ \\
Copeptin $^{\mathrm{a}}$ or cTnT & $10 / 10(100)$ & $34 / 37(91.9)$ & $60 / 66(90.9)$ \\
Copeptin $^{\mathrm{b}}$ or cTnT & $10 / 10(100)$ & $34 / 37(91.9)$ & $62 / 66(93.9)$ \\
Copeptin $^{\mathrm{c}}$ or cTnT & $10 / 10(100)$ & $36 / 37(97.3)$ & $64 / 66(97.0)$ \\
Copeptin $^{\mathrm{a}}$ or hs-cTnT & $10 / 10(100)$ & $37 / 37(100)$ & $65 / 66(98.5)$ \\
Copeptin $^{\mathrm{b}}$ or hs-cTnT & $10 / 10(100)$ & $37 / 37(100)$ & $65 / 66(98.5)$ \\
Copeptin $^{\mathrm{c}}$ or hs-cTnT & $10 / 10(100)$ & $37 / 37(100)$ & $65 / 66(98.5)$ \\
\hline
\end{tabular}

demonstrate that in patients with successfully reperfused ST-elevation AMI within $12 \mathrm{~h}$ of symptom onset, the release pattern of copeptin is distinctively different from currently available cardiac biomarkers. Copeptin levels peaked within the first hour after symptom onset and fell to normal ranges after $10 \mathrm{~h}$. In contrast, levels of CK-MB, cTnT, and hs-cTnT peaked after more than $14 \mathrm{~h}$ and decreased more gradually. Furthermore, a higher copeptin level on admission is related to a shorter time from symptom onset to reperfusion and a lower systolic blood pressure.

Copeptin is derived from the C-terminal portion of the precursor of vasopressin, one of the most important hormones in regulating osmotic and cardiovascular homeostasis and also released in response to acute endogenous stress [6, 13]. Synthesized in the hypothalamus from the precursor peptide pre-provasopressin, both peptides are released by the neurohypophysis into the circulation. While its exact function is largely unknown, copeptin acts as a stable surrogate marker for vasopressin [10]. Furthermore, copeptin has been reported as a biomarker in a variety of clinical conditions including sepsis, lower respiratory tract infections, and acute exacerbations of chronic obstructive pulmonary disease [14-19]. The exact trigger for copeptin release in AMI is unknown. Generally considered a marker of acute endogenous stress, copeptin may be released in response to stress occurring with the onset of AMI [8, 13]. However, copeptin also responds rapidly to changes in fluid status and plasma osmolality [20, 21]. Our findings, indicating that higher copeptin levels are independently related to a lower systolic blood pressure, are consistent with these reports. Therefore, the quick elevation of copeptin levels in AMI may also be triggered by hemodynamic changes occurring after a drop in blood pressure, or even earlier with elevation of left ventricular end-diastolic pressure after coronary occlusion [22].

This study confirms and extends the findings of recent previous studies, which reported that copeptin levels in AMI patients were maximal on admission in contrast to cTnT [7, 8] and dropped to a plateau level after the first day [23]. The current study, however, is the first to describe the temporal release pattern of copeptin in detail over the first 


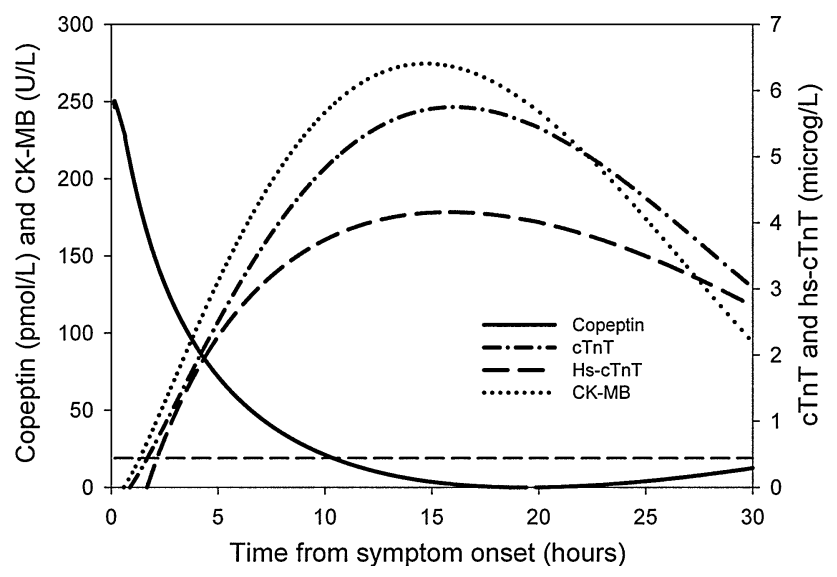

Fig. 1 Temporal release pattern of copeptin versus CK-MB, cTnT, and hs-cTnT. The dashed horizontal line represents the upper reference limit (99th percentile) for copeptin. CK-MB, creatine kinase isoenzyme; cTnT, cardiac troponin T; hs-cTnT, high-sensitivity cardiac troponin $\mathrm{T}$

$24 \mathrm{~h}$ after symptom onset in AMI and in comparison to the release patterns of CK-MB, cTnT, and hs-cTnT. Copeptin levels in the current study were approximately fourfold higher than in these previous studies, most likely because our population consisted of patients with ST-elevation AMI only instead of a mixed population of AMI with and without ST-elevation. It has been reported that copeptin levels are higher for ST-elevation AMI than for non-STelevation AMI [8].

To date, conventional cardiac biomarkers have limited ability in immediately ruling out AMI in patients presenting early with symptoms that are suggestive for an AMI but with non-diagnostic findings on ECG. The current findings together with the previous studies suggest that copeptin may be a potentially valuable marker on top of cTnT for the detection of AMI. Copeptin levels are not elevated in patients with exercise-induced ischemia [20] but are significantly higher in patients with a suspected acute coronary syndrome (ACS) presenting to an emergency department in those with a final diagnosis of AMI than in those with a different final diagnosis, including unstable angina and other cardiac and non-cardiac causes of chest pain $[7,8]$. In these patients, adding a copeptin to a cTnT measurement on admission improved the discriminative value compared to a cTnT measurement alone and was of superior value in ruling out AMI. With the combination of copeptin and cTnT, the negative predictive value of a single measurement on admission increased from 88.5 to 95.8\% for all AMI suspects and from 82.4 to $92.4 \%$ for suspects presenting within $3 \mathrm{~h}$ after symptom onset [8]. The current study illustrates and substantiates these findings, since we confirm that, in patients with an AMI, copeptin is already strongly elevated in the very early phase, while cTnT levels are still low. Because troponin assays lack sensitivity in the early hours after onset of AMI, adding a marker that is sensitive in these early hours and acts independently from cardiomyocyte injury to this conventional biomarker of myocardial necrosis may complement and improve the diagnostic accuracy of a measurement on admission.

Consistent with the other studies [3, 24], this study indicates that CK-MB and cTnT begin to rise within several hours after the onset of myocardial injury and reach their peak value in the first $24 \mathrm{~h}$. Concordantly, hs-cTnT follows a similar release pattern as cTnT, despite a higher sensitivity and improved precision at the lower limit of detection [25-27]. The only conventional cardiac biomarker that could approach the early presence of marker levels above normal ranges is myoglobin, whose levels begin to rise $1 \mathrm{~h}$ after myocardial injury [3]. Despite its quick release into the circulation, however, myoglobin is not of additional value in a diagnostic strategy including cardiac troponin and is not recommended as a diagnostic biomarker in the routine clinical practice [28]. Whether copeptin in conjunction with a high-sensitivity troponin assay improves the diagnosis of ACS as suggested [7, 29] deserves further investigation.

\section{Limitations}

Several limitations should be acknowledged as a result of the inclusion and exclusion criteria of the present main study. First, specificity could not be calculated for copeptin and cardiac biomarkers in this study as all patients had a final diagnosis of ST-elevation AMI. Previous studies have indicated that copeptin has a low specificity and is more appropriate as a biomarker to rule out AMI. Second, assessment of copeptin has no value in the clinical practice when ST-elevations are present on the ECG, but it is of potential interest when patients present early and other electrocardiographic and laboratory parameters are yet at normal levels. The temporal release pattern described here is only investigated for ST-elevation AMI and not for nonST-elevation AMI. In addition, the infarct-related artery was (nearly) completely occluded at presentation in all patients. In a more unselected AMI population with STelevation, where a significant proportion of patients present with an open infarct-related artery, it can be speculated that baseline copeptin levels are lower, similar to the lower copeptin levels found in non-ST-elevation AMI [8], in which the infarct-related artery is usually open. Further studies in AMI patients with and without ST-elevation could clarify whether the lower copeptin levels in non-STelevation AMI is the result of patency of the infarct-related artery or of a longer time from symptom onset to admission. Third, primary PCI successfully achieved reperfusion through the infarct-related artery in all patients. Whether 
the quick normalization of copeptin levels is the mere result of increasing time after onset of AMI or is a specific response to successful primary PCI or other forms of reperfusion requires further investigation. Fourth, the limited number of clinical events in this patient group did not allow us to assess relationships between copeptin levels and the clinical outcome. Copeptin levels on admission have already been reported to be a strong prognostic marker of mortality in cardiovascular patients (with and without heart failure) surviving an AMI [23, 30, 31]. Fifth, we are unable to explain why BMI is a strong determinant of copeptin levels on admission. While the same is observed for BMI and N-terminal pro-B-type natriuretic peptide [32], the inverse relation between BMI and biomarkers is poorly understood. Finally, we did not analyze the temporal release pattern of myoglobin as this was not a routine measurement in our center and there was insufficient frozen material stored to allow this additional analysis.

In conclusion, copeptin is elevated in the early hours after the onset of an ST-elevation AMI when other conventional cardiac biomarkers, including CK-MB and cTnT, are still low.

Acknowledgments The study was funded by the Interuniversity Cardiology Institute of the Netherlands (ICIN). Additional unrestricted grants were received from Janssen-Cilag, Tilburg, the Netherlands, and B.R.A.H.M.S GmbH, Hennigsdorf, Germany. B.R.A.H.M.S GmbH holds patent rights on copeptin. JS is an employee of B.R.A.H.M.S GmbH.

Open Access This article is distributed under the terms of the Creative Commons Attribution Noncommercial License which permits any noncommercial use, distribution, and reproduction in any medium, provided the original author(s) and source are credited.

\section{References}

1. Thygesen K, Alpert JS, White HD et al (2007) Universal definition of myocardial infarction. Circulation 116:2634-2653. doi: 10.1161/CIRCULATIONAHA.107.187397

2. Apple FS, Jesse RL, Newby LK, Wu AH, Christenson RH (2007) National academy of clinical biochemistry and IFCC committee for standardization of markers of cardiac damage laboratory medicine practice guidelines: analytical issues for biochemical markers of acute coronary syndromes. Circulation 115:e352e355. doi:10.1161/CIRCULATIONAHA.107.182881

3. Morrow DA, Cannon CP, Jesse RL et al (2007) National academy of clinical biochemistry laboratory medicine practice guidelines: clinical characteristics and utilization of biochemical markers in acute coronary syndromes. Clin Chem 53:552-574. doi:10.1373/ clinchem.2006.084194

4. Keller T, Post F, Tzikas S et al (2010) Improved outcome in acute coronary syndrome by establishing a chest pain unit. Clin Res Cardiol 99:149-155. doi:10.1007/s00392-009-0099-9

5. Bauer T, Hoffmann R, Jünger C et al (2009) Efficacy of a 24-h primary percutaneous coronary intervention service on outcome in patients with ST elevation myocardial infarction in clinical practice. Clin Res Cardiol 98:171-178. doi:10.1007/s00392008-0738-6

6. Itoi K, Jiang YQ, Iwasaki Y, Watson SJ (2004) Regulatory mechanisms of corticotropin-releasing hormone and vasopressin gene expression in the hypothalamus. $\mathrm{J}$ Neuroendocrinol 16:348-355. doi:10.1111/j.0953-8194.2004.01172.x

7. Keller T, Tzikas S, Zeller T et al (2010) Copeptin improves early diagnosis of acute myocardial infarction. J Am Coll Cardiol 55:2096-2106. doi:10.1016/j.jacc.2010.01.029

8. Reichlin T, Hochholzer W, Stelzig C et al (2009) Incremental value of copeptin for rapid rule out of acute myocardial infarction. J Am Coll Cardiol 54:60-68. doi:10.1016/j.jacc.2009.01.076

9. Voors AA, Belonje AM, Zijlstra F et al (2010) A single dose of erythropoietin in ST-elevation myocardial infarction. Eur Heart J 31:2593-2600. doi:10.1093/eurheartj/ehq304

10. Morgenthaler NG, Struck J, Alonso C, Bergmann A (2006) Assay for the measurement of copeptin, a stable peptide derived from the precursor of vasopressin. Clin Chem 52:112-119. doi: 10.1373/clinchem.2005.060038

11. Smilde TD, van Veldhuisen DJ, Navis G, Voors AA, Hillege HL (2006) Drawbacks and prognostic value of formulas estimating renal function in patients with chronic heart failure and systolic dysfunction. Circulation 114:1572-1580. doi:10.1161/ CIRCULATIONAHA.105.610642

12. Royston P, Altman DG (1994) Regression using fractional polynomials of continuous covariates: parsimonious parametric modelling (with Discussion). Appl Stat 43:429-467

13. Katan M, Morgenthaler N, Widmer et al (2008) Copeptin, a stable peptide derived from the vasopressin precursor, correlates with the individual stress level. Neuro Endocrinol Lett 29:341-346

14. Morgenthaler NG, Struck J, Jochberger S, Dunser MW (2008) Copeptin: clinical use of a new biomarker. Trends Endocrinol Metab 19:43-49. doi:10.1016/j.tem.2007.11.001

15. Jochberger S, Morgenthaler NG, Mayr VD et al (2006) Copeptin and arginine vasopressin concentrations in critically ill patients. J Clin Endocrinol Metab 91:4381-4386. doi:10.1210/jc.20052830

16. Morgenthaler NG, Muller B, Struck J, Bergmann A, Redl H, Christ-Crain M (2007) Copeptin, a stable peptide of the arginine vasopressin precursor, is elevated in hemorrhagic and septic shock. Shock 28:219-226. doi:10.1097/SHK.0b013e318033e5da

17. Muller B, Morgenthaler N, Stolz D et al (2007) Circulating levels of copeptin, a novel biomarker, in lower respiratory tract infections. Eur J Clin Invest 37:145-152. doi:10.1111/j.1365-2362. 2007.01762.x

18. Sharshar T, Blanchard A, Paillard M, Raphael JC, Gajdos P, Annane D (2003) Circulating vasopressin levels in septic shock. Crit Care Med 31:1752-1758. doi:10.1097/01.CCM.0000063046. 82359.4A

19. Stolz D, Christ-Crain M, Morgenthaler NG et al (2007) Copeptin, C-reactive protein, and procalcitonin as prognostic biomarkers in acute exacerbation of COPD. Chest 131:1058-1067. doi:10.1378/ chest.06-2336

20. Staub D, Morgenthaler NG, Buser C et al (2009) Use of copeptin in the detection of myocardial ischemia. Clin Chim Acta 399:69-73. doi:10.1016/j.cca.2008.09.016

21. Szinnai G, Morgenthaler NG, Berneis K et al (2007) Changes in plasma copeptin, the c-terminal portion of arginine vasopressin during water deprivation and excess in healthy subjects. J Clin Endocrinol Metab 92:3973-3978. doi:10.1210/jc.2007-0232

22. Pirzada FA, Ekong EA, Vokonas PS, Apstein CS, Hood WB Jr (1976) Experimental myocardial infarction. XIII. Sequential changes in left ventricular pressure-length relationships in the acute phase. Circulation 53:970-975 
23. Khan SQ, Dhillon OS, O'Brien RJ et al (2007) C-terminal provasopressin (copeptin) as a novel and prognostic marker in acute myocardial infarction: Leicester acute myocardial infarction peptide (LAMP) study. Circulation 115:2103-2110. doi:10.1161/ CIRCULATIONAHA.106.685503

24. Antman EM, Anbe DT, Armstrong PW et al (2004) ACC/AHA guidelines for the management of patients with ST-elevation myocardial infarction: a report of the American college of cardiology/American Heart Association Task Force on Practice Guidelines (Committee to Revise the 1999 Guidelines for the Management of Patients with Acute Myocardial Infarction). J Am Coll Cardiol 44:671-719. doi:10.1016/j.jacc.2004.07. 002

25. Keller T, Zeller T, Peetz D et al (2009) Sensitive troponin I assay in early diagnosis of acute myocardial infarction. N Engl J Med 361:868-877. doi:10.1056/NEJMoa0903515

26. Reichlin T, Hochholzer W, Bassetti S et al (2009) Early diagnosis of myocardial infarction with sensitive cardiac troponin assays. N Engl J Med 361:858-867. doi:10.1056/NEJMoa0900428

27. Kurz K, Giannitsis E, Becker M, Hess G, Zdunek D, Katus HA (2011) Comparison of the new high sensitive cardiac troponin $T$ with myoglobin, h-FABP and cTnT for early identification of myocardial necrosis in the acute coronary syndrome. Clin Res Cardiol 100:209-215. doi:10.1007/s00392-010-0230-y
28. Eggers KM, Oldgren J, Nordenskjold A, Lindahl B (2004) Diagnostic value of serial measurement of cardiac markers in patients with chest pain: limited value of adding myoglobin to troponin I for exclusion of myocardial infarction. Am Heart J 148:574-581. doi:10.1016/j.ahj.2004.04.030

29. Meune C, Zuily S, Wahbi K, Claessens YE, Weber S, ChenevierGobeaux C (2011) Combination of copeptin and high-sensitivity cardiac troponin $\mathrm{T}$ assay in unstable angina and non-ST-segment elevation myocardial infarction: a pilot study. Arch Cardiovasc Dis 104:4-10. doi:10.1016/j.acvd.2010.11.002

30. Kelly D, Squire IB, Khan SQ et al (2008) C-terminal provasopressin (copeptin) is associated with left ventricular dysfunction, remodeling, and clinical heart failure in survivors of myocardial infarction. J Card Fail 14:739-745. doi:10.1016/j.cardfail.2008. 07.231

31. Voors AA, von Haehling S, Anker SD et al (2009) C-terminal provasopressin (copeptin) is a strong prognostic marker in patients with heart failure after an acute myocardial infarction: results from the OPTIMAAL study. Eur Heart J 30:1187-1194. doi:10.1093/eurheartj/ehp098

32. Das SR, Drazner MH, Dries DL et al (2005) Impact of body mass and body composition on circulating levels of natriuretic peptides: results from the Dallas Heart Study. Circulation 112:2163-2168. doi:10.1161/CIRCULATIONAHA.105.555573 